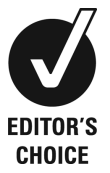

1 Department of Pediatrics, Midland Regional Hospital, Westmeath, Ireland ${ }^{2}$ Department of Histopathology, Our Lady's Children's Hospital, Dublin Ireland

${ }^{3}$ Royal College of Surgeons, Ireland

\section{Correspondence to} Dr Birendra Rai, drbirendrarai@gmail.com

Accepted 4 August 2014

\title{
Mandibular swelling in a 5-year-old child - mandibular myofibroma
}

\author{
Birendra Rai, ${ }^{1}$ Evodia Ludusan, ${ }^{1}$ Brianán McGovern, ${ }^{2}$ Farhana Sharif ${ }^{1,3}$
}

\begin{abstract}
SUMMARY
A 5-year-old girl of African descent presented with a history of progressive painless swelling on the right side of the jaw since the past 2-3 months. Orthopantomogram showed a radiolucent lesion near the angle of the mandible. Subsequent CT scan revealed a $2 \mathrm{~cm} \times 2 \mathrm{~cm}$ radiolucent lesion with intense periosteal reaction surrounding the lesion and destruction of the overlying cortex. Radiological perplexity aroused regarding the possibility of eosinophilic granuloma or some other malignant lesion. Incisional biopsy performed and microscopy showed spindle cell tumor. Immunohistochemistry confirmed it as myofibroma. Myofibroma is a rare benign tumour involving mesenchyme. Involvement of the mandible is rare. Radiological presentation with strong periosteal reaction is a rarity and has rarely been reported in the medical literature. We conclude that intraosseous myofibroma can sometimes have strong periosteal reaction and careful radiological evaluation is a prerequisite for accurate diagnosis and to avoid unnecessary aggressive therapy.
\end{abstract}

\section{BACKGROUND}

Mandibular intraosseous myofibroma is an extremely rare tumour in paediatric age group. It is a benign mesenchymal tumour that presents as a radiolucent lesion while originating as intraosseous tumour. Strong periosteal reaction around the lesion, as in our case, has rarely been reported in medical literature. Besides this, positivity for CD 34 stain in immunohistochemistry of the biopsied lesion re-emphasises the recently published aetiopathogenetic mechanism of haemangiopericytomatous origin of myofibroma, ${ }^{1}$ but it warrants further confirmation by more future studies.

\section{CASE PRESENTATION}

A 5-year-old girl of African descent presented with a history of progressive swelling on the right side of the lower jaw since the past 2-3 months. She had no pain associated with the swelling. She was thriving well with her weight and height plotting on the 75 th centile (UK-WHO growth chart). She denied any history of trauma, fever, weight loss or other constitutional symptoms. She had never encountered any problem while chewing solid food. She was born at full term by normal delivery and had no significant history of relevance. She had no known drug allergy and her vaccinations were up to date. There was no family history of any malignancy.
On examination a non-tender round swelling was noted around angle of the mandible on the right side. It measured approximately $2 \mathrm{~cm} \times 2 \mathrm{~cm}$ in diameter. Swelling was hard, non-mobile, fixed to underlying bone but was not adhered to superficial skin. There were no signs of inflammation overlying the swelling. Systemic examination was within normal limits with no lymphadenopathy or organomegaly anywhere in the body. Initial blood tests revealed normal full blood counts, C reactive protein, erythrocyte sedimentation rate, urea, creatinine, lactate dehydrogenase and electrolytes.

Orthopantomogram (OPG) showed evidence of a well-defined radiolucency within the right side of the body of the mandible, lying between the roots of the fifth and sixth right inferior teeth (figure 1). There was a slight loss of clarity of the lamina dura of an unerupted tooth, with destruction of the lamina dura of one of the roots of the adjacent molar tooth. These findings raised the possibility of Langerhans cell histiocytosis (eosinophilic granuloma). Subsequent CT scan confirmed the presence of a soft tissue mass arising from within the medullary cavity of the right side of the mandible. It measured approximately $1.8 \mathrm{~cm}$ in maximum diameter (figure 2). It contained no internal calcification, and showed moderate diffuse enhancement with contrast. Lesion had caused extensive destruction of the overlying cortex (figure 3), with strong periosteal reaction (figure 4) and a significant proportion of lesion's mass extended into the overlying soft tissues. Still the provisional diagnosis was eosinophilic granuloma but possibility of some underlying malignant process in the context of strong periosteal reaction, could not be ruled out. Skull X-ray, chest X-ray and abdominal ultrasound were reportedly normal.

She underwent incisional biopsy of the lesion under general anaesthesia. Histopathological examination of biopsied tissue revealed fragments of a spindle cell proliferation. The spindle cells, arranged in vague fascicles, had distinct cellular borders, elongated nuclei with abundant eosinophilic cytoplasm (figure 5). A few polygonal cells were also noted with hyperchromatic nuclei and scant cytoplasm. Mitotic figures and atypical nuclear forms were absent. A rich vascular plexus of slightly ectatic thin-walled small calibre vessels was noted.

Immunohistochemical stains showed reactivity to smooth muscle actin (SMA; figure 6) and no reactivity to $S-100$ protein or desmin. These findings were consistent with myofibroma. Stain for CD 34 was positive (figure 7). 


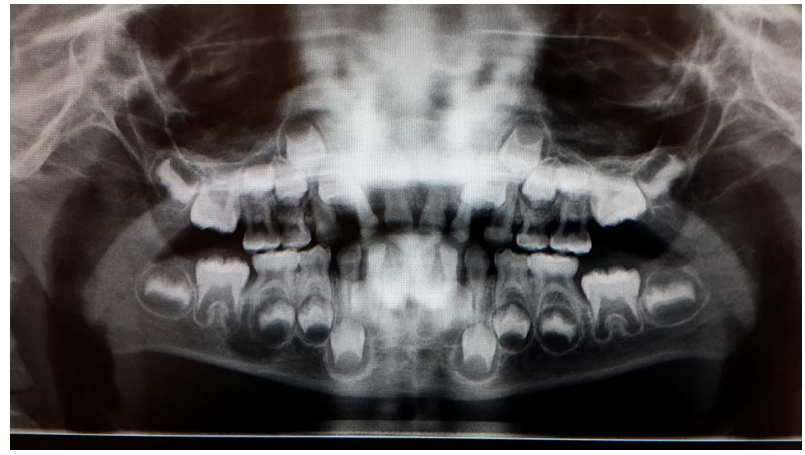

Figure 1 Orthopantomogram showing radiolucent lesion in right mandible.

\section{DIFFERENTIAL DIAGNOSIS}

Myofibroma presents a broad range of differential diagnosis, including benign and malignant neoplasms. Important ones are listed below.

- Inflammatory myofibroblastic tumour (IMT)

- Nodular fasciitis

- Eosinophilic granuloma

- Fibrous histiocytoma

- Neurofibroma

- Ameloblastoma

- Leiomyoma/leiomyosarcoma

- Rhabdomyosarcoma

- Osteogenic sarcoma of mandible

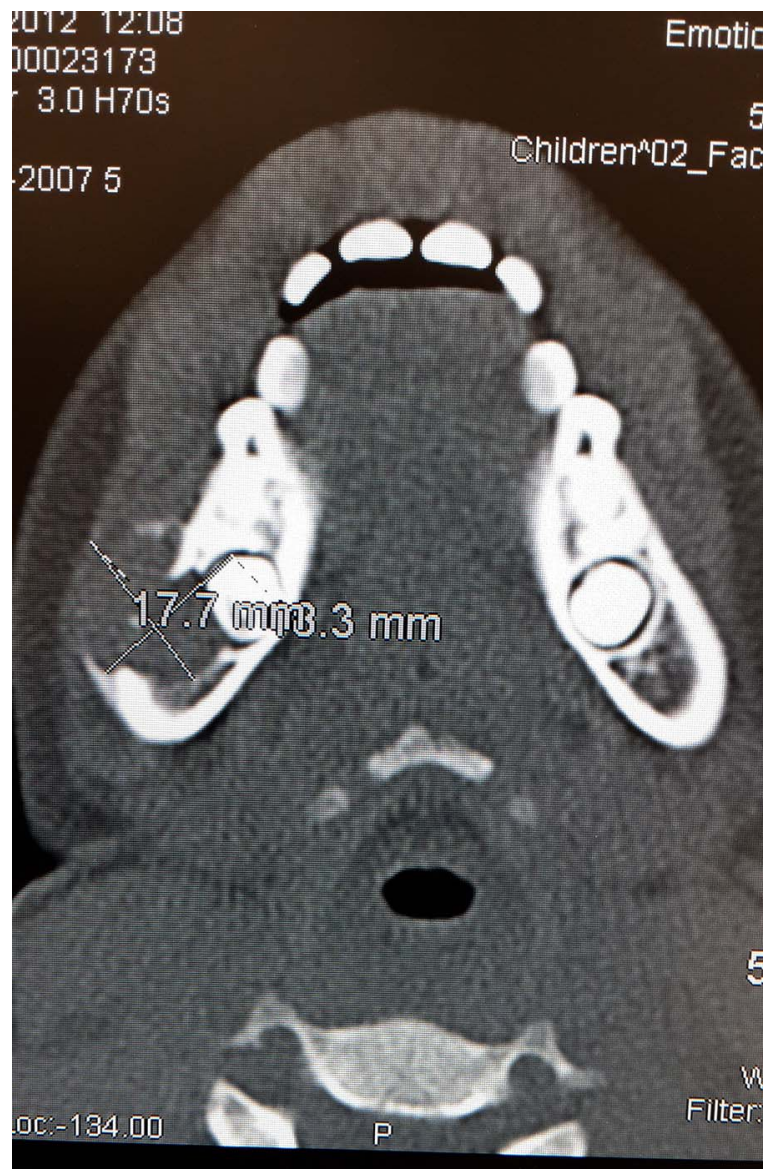

Figure 2 CT scan showing intraosseous mass originating from the right mandible and extending into the overlying soft tissue.

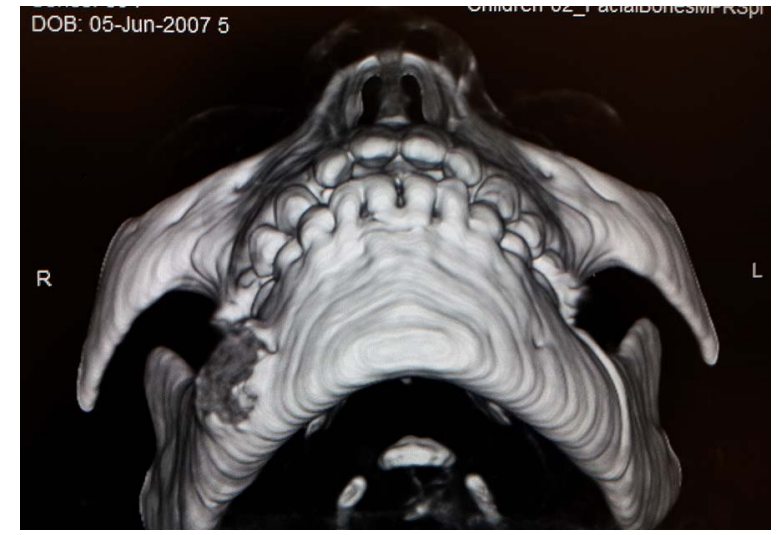

Figure 3 CT scan three-dimensional showing erosion of overlying cortex surrounding the lesion.

- Myopericytoma/hemangiomyopericytoma

- Squamous cell carcinoma

- Burkett's Lymphoma

- Secondary metastases from other oral or systemic primary malignancy

- Leukaemia

\section{TREATMENT}

She underwent complete surgical excision of the mass with no haemostatic difficulty.

\section{OUTCOME AND FOLLOW-UP}

Two year follow-up has not shown any recurrence of the swelling.

\section{DISCUSSION}

Myofibroma is a rare benign mesenchymal tumour which occurs in patients of a wide range of age group from infancy to elderly. Unlike its adult counterpart (desmoid tumours), paediatric myofibroma is mostly benign $(85 \%)$ in nature. ${ }^{2}$ Myofibroma can arise from skin, soft tissue, muscle, bone or even internal organs with the soft tissue origin being the most common. One-third of lesions arise in the head and neck regions with oral cavity, tongue, buccal mucosa, maxilla or palate being favourable sites of involvement. Involvement of the mandible is very rare. Myofibroma has also been reported originating from orbit and parotid glands. $^{3}$

The cause of the tumour is still unknown though recent studies have suggested its probable origin from myopericytes and perivascular mesenchymal cells. ${ }^{1}$ Though most of the cases are sporadic, autosomal dominant and recessive inheritance has been described in literature. ${ }^{3-5}$ The certainty of these inheritance patterns is unreliable and is difficult to prove due to rarity of the familial incidence of this tumour.

Most common presentation is asymptomatic swelling of soft tissue or bone that can rarely be painful. ${ }^{6}$ Lesion can be either solitary or multiple. Myofibroma is the term used to describe solitary lesion whereas multilocular lesions are referred to as myofibromatosis. Among patients with the mandibular involvement $70 \%$, present with a unilocular intraosseous lesion.

Keeping in view the benign nature of myofibroma in paediatric patients, Its differentiation with several other similarly presenting malignant lesion of the mandible and surrounding structures (vide differential diagnosis) is of paramount importance to avoid unnecessary aggressive management. Unlike 


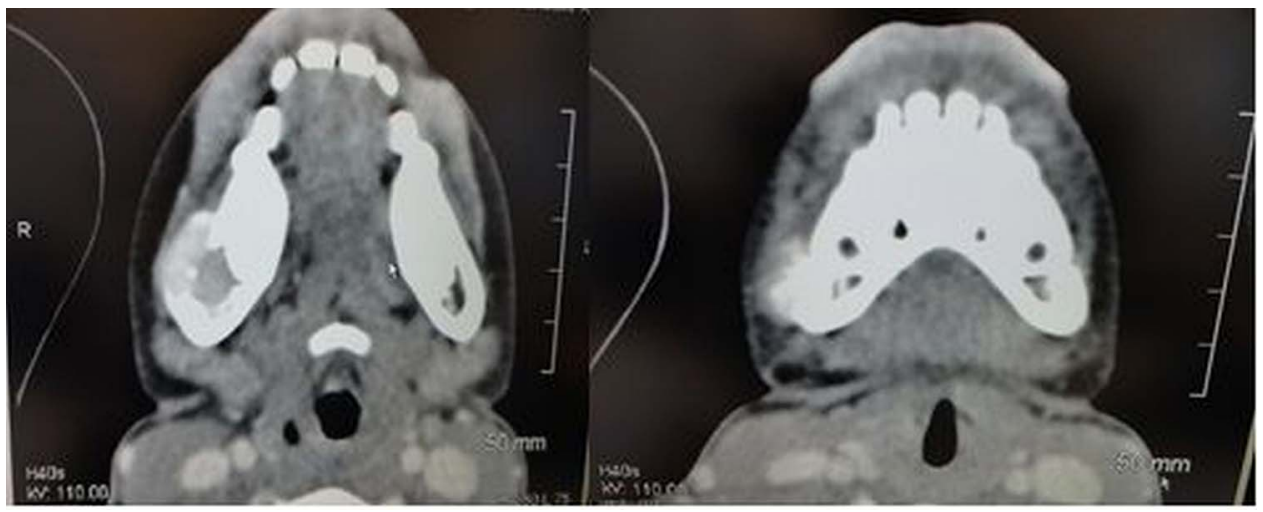

Figure 4 Image showing strong periosteal reaction around intraosseous myofibroma.

paediatric myofibroma, a study involving adult patients has revealed high incidence of invasive fibroblastic tumour in older age group patients. ${ }^{7}$

The importance of accurate radio imaging is indispensable in delineating the extent of lesion prior to any form of surgical intervention. Initial panoramic radiograph (orthopantomogram) of the jaw bones often shows radiolucent lesion inside medullary cavities of the involved bone. CT scan of the face is the investigation of choice to depict mandibular lesion scrupulously. The radiolucent lesion of the mandible in our case was seen to be associated with strong periosteal reaction that embroiled the differentials more towards aggressive malignant lesions. Very minimal fraction of patient with mandibular myofibroma shows erosion of overlying cortex. Our case had marked erosion of overlying cortex of the mandible.

Meticulous microscopy and immunohistochemistry of the biopsied tissue is of paramount importance in extricating accurate diagnosis out of the several possible similarly presenting benign to malignant lesions. Gross examination reveals firm, homogenous or whorled, grayish white fibrous mass of varying diameters. ${ }^{8}$ Histologically a nodular growth with biphasic internal architecture is typically seen in myofibroma. ${ }^{9} 10$ The peripheral paucicellular region of the growth comprises of fascicles and whorls of short spindle cells with elongated nuclei and

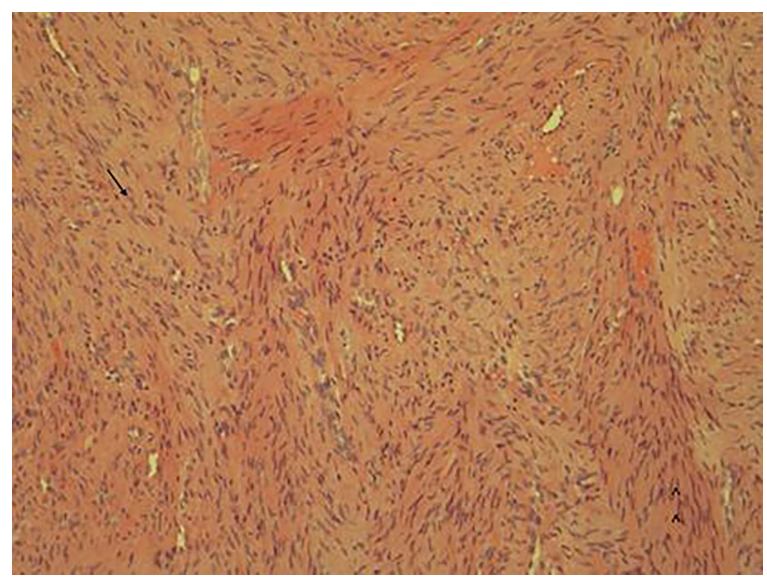

Figure 5 Medium power (10x) magnification view showing fascicular arrangement of cells and biphasic pattern of growth of immature-appearing plump spindled tumour cells (arrow) associated with numerous thin-walled, branching vessels, and more mature, spindled tumour cells with abundant eosinophilic cytoplasm (arrow-heads). eosinophilic cytoplasm. Central relatively more cellular zone of the growth is composed of primitive round, polygonal or spindle cells with hyperchromatic nuclei and scant cytoplasm. This micronodular zoning phenomenon is distinct for myofibroma. ${ }^{11}$ The cells in the central zone are often seen to arrange around thin-walled ectatic haemangiopericytic vessels. Areas of necrosis, calcification and hyalinisation are not uncommon in the central zone of the growth highlighting its eventual spontaneous regression in some percentages of the cases. ${ }^{12}$ Nuclear atypia, prominent mitotic activity and 'Herring bone pattern' point towards more malignant lesions such as fibrosarcoma. ${ }^{13} 14$ Cells are arranged in a storiform pattern in fibrous histiocytoma whereas a variable background of inflammatory cells helps differentiate IMT from myofibroma. ${ }^{9}$ Mason trichrome stain helps differentiating myofibroma from leiomyomatous lesions as myofibromatous lesions has much more collagenous component than leiomyoma or other smooth muscle tumours. ${ }^{15}$

Immunocytochemistry further differentiates myofibroma from other lesions as spindle cells in myofibroma stain positive for SMA, muscle specific actin (MSA) and vimentin. Stains for S-100 (neurofibroma), Desmin (malignant smooth muscle and fibroblastic tumours such as leiomyosarcoma and fibrosarcoma), CD34 (hemangiopericytoma) and ALK 1 (inflammatory myofibroblastic tumour) are negative in myofibroma. ${ }^{8} 16-18$ The presence of S-100 protein indicates tumour of nerve cell origin. Though CD 34 stain positivity favours the diagnosis of hemangiopericytoma more than myofibroma, study have suggested

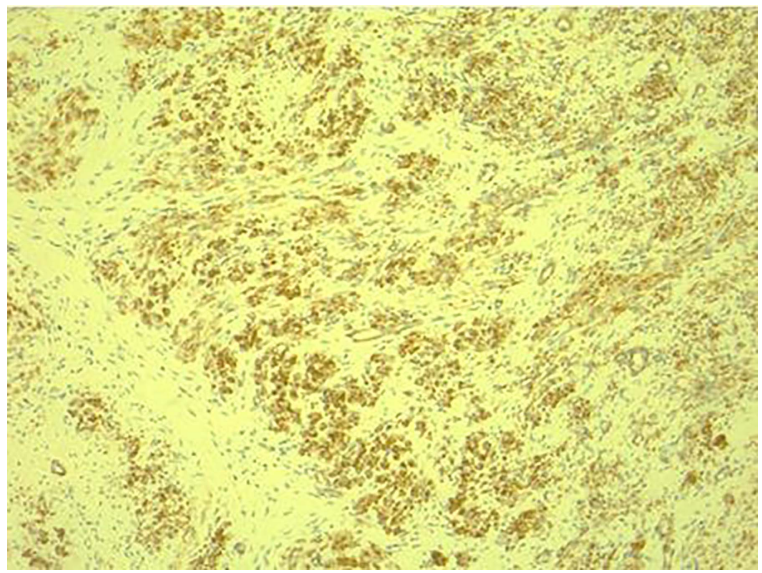

Figure 6 Immunohistochemical stain for smooth muscle actin $(\alpha-S M A)$ shows convincing reactivity. 


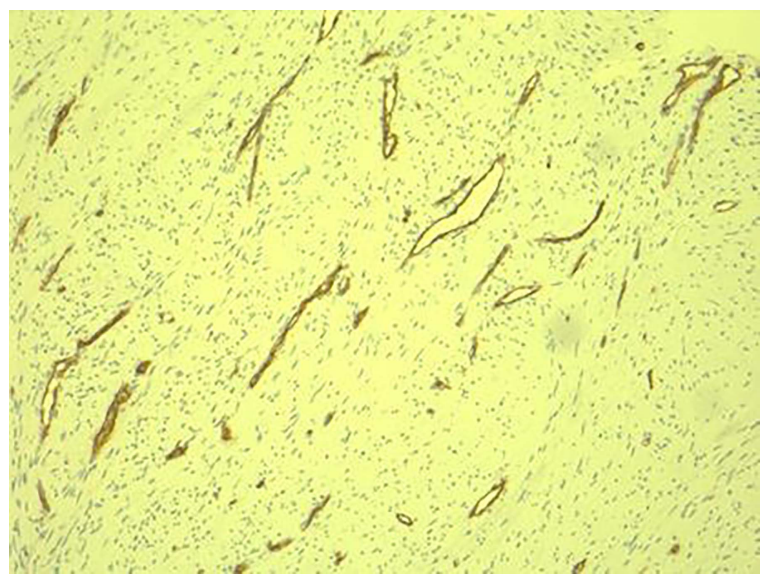

Figure 7 Immunohistochemical stain for CD34 highlights numerous thin-walled, branching vessels within the tumour.

similar origin of both these tumours from perivascular mesenchyme with spectrum of growth pattern of hemangiopericytoma frequently overlapping with myofibroma. ${ }^{1}$ Differentiation should be based on predominant growth pattern and it was of myofibroma with biphasic nodular growth in our case.

Treatment is conservative if the lesion is solitary and site warrants its removal due to impending cosmetic or physical complications. Some of the myofibromatous lesions regress spontaneously. ${ }^{19}$ Recurrence after excision is rare though it has been reported in few earlier study. ${ }^{19}{ }^{20}$ Recurrences were solely ascribed to anatomical complexity in the complete removal of the tumour, such as the tumour in infratemporal fossa, skull base and multiple tumours. ${ }^{19}$ Incomplete surgical excision is also an important cause of recurrence. ${ }^{19}$ Recurrences responds well to further curettage. ${ }^{20}$

We conclude that intraosseous myofibroma, though benign in nature can sometime mystify its identity due to radiological similarity with other morbid lesions as in our case. Strong periosteal reaction around lesions of intraosseous myofibroma has rarely been reported in medical literature.

\section{Learning points}

- Involvement of mandible is rare in myofibroma. Thus appropriate clinical suspicion is required to evaluate it at an early stage of presentation.

- It may present as aggressive looking lesion on radiograph with strong periosteal reaction, but it can still be benign in nature as malignant features are rarely seen in paediatric myofibroma.

- Accurate microscopy and immunohistochemistry of the biopsied lesion is mandatory to correctly diagnose myofibroma and avoid further aggressive therapy.

- Recurrence after complete excision is rare.
Contributors BR involved in the literature review and manuscript drafting, revision of the manuscript; EL involved in the patient management and follow up; BMcG involved in the provided histopathology and immunohistochemistry images and descriptions; FS involved in the diagnosis, supervision and critical review of the intellectual content of the manuscript.

\section{Competing interests None.}

Patient consent Obtained.

Provenance and peer review Not commissioned; externally peer reviewed.

\section{REFERENCES}

1 Dray MS, McCarthy SW, Palmer AA, et al. Myopericytoma: a unifying term for a spectrum of tumours that show overlapping features with myofibroma. A review of 14 cases. J Clin Pathol 2006;59:67-73.

2 Palumbo JS, Zwerdling T. Soft tissue sarcomas of infancy. Semin Perinatol 1999:23:299-309.

3 Enzinger FM, Weiss SW, Goldblum JR. eds. Enzinger and Weiss soft tissue tumors. St Louis: Mosby, 2001:357-63.

4 Gopal M, Chahal G, Al-Rifai Z, et al. Infantile myofibromatosis. Pediatr Surg Int 2008:24:287-91.

5 Jennings TA, Duray PH, Collins FS, et al. Infantile myofibromatosis. Evidence for an autosomal-dominant disorder. Am J Surg Pathol 1984;8:529-38.

6 Shibuya Y, Takeuchi J, Sakaguchi H, et al. Myofibroma of the mandible. Kobe J Med Sci 2008:54:E169-73.

7 Conley J, Healey WV, Stout AP. Fibromatosis of the head and neck. Am J Surg 1966;112:609-14.

8 Foss RD, Ellis GL. Myofibromas and myofibromatosis of the oral region: a clinicopathologic analysis of 79 cases. Oral Surg Oral Med Oral Pathol Oral Radiol Endod 2000;89:57-65.

9 Oudijk L, den Bakker MA, Hop WC, et al. Solitary, multifocal and generalized myofibromas: clinicopathological and immunohistochemical features of 114 cases. Histopathology 2012;60:E1-11.

10 Myofibroma/Myofibromatosis - Surgical Pathology Criteria-Stanford University School of Medicine. http://surgpathcriteria.stanford.edu/softfib/myofibroma_ myofibromatosis/

11 Sundaravel $\mathrm{S}$, Anuthama K, Prasad H, et al. Intraosseous myofibroma of mandible: a rarity of jaws: with clinical, radiological, histopathological and immunohistochemical features. J Oral Maxillofac Pathol 2013;17:121-5.

12 Gardner JM. Soft tissue Fibroblastic/myofibroblastic tumors Myofibroma/ myofibromatosis. 26 April 2013. http://www.pathologyoutlines.com/topic/ softtissuemyofibroma.html

13 Allon I, Vered M, Buchner A, et al. Central (intraosseous) myofibroma of the mandible: clinical, radiologic, and histopathologic features of a rare lesion. Oral Surg Oral Med Oral Pathol Oral Radiol Endod 2007;103:e45-53.

14 Kahn LB, Vigorata V. Fibrosarcoma. In: Fletcher CD, Unni KK, eds. World Health Organization classification of tumors. Pathology and genetics. Tumours of soft tissue and bone. Lyon: IARC Press, 2002:289.

15 Chang JY, Kessler HP. Masson trichrome stain helps differentiate myofibroma from smooth muscle lesions in the head and neck region. J Formos Med Assoc 2008; 107:767-73.

16 Azevedo Rde S, Pires FR, Della Coletta R, et al. Oral myofibromas: report of two cases and review of clinical and histopathologic differential diagnosis. Oral Surg Oral Med Oral Pathol Oral Radiol Endod 2008;105:e35-40.

17 Persaud TO, Nik NA, Keating RF, et al. Solitary orbital infantile myofibroma: a case report and review of the literature. J AAPOS 2006;10:283-4.

18 Vered M, Allon I, Buchner A, et al. Clinico-pathologic correlations of myofibroblastic tumors of the oral cavity. II. Myofibroma and myofibromatosis of the oral soft tissues. J Oral Pathol Med 2007:36:304-14.

19 Beck JC, Devaney KO, Weatherly RA, et al. Pediatric myofibromatosis of the head and neck. Arch Otolaryngol aryngol Head Neck Surg 1999;125:39-44.

20 Sedghizadeh PP, Allen CM, Kalmar JR, et al. Solitary central myofibroma presenting in the gnathic region. Ann Diagn Pathol 2004:8:284-9. 
Copyright 2014 BMJ Publishing Group. All rights reserved. For permission to reuse any of this content visit http://group.bmj.com/group/rights-licensing/permissions.

BMJ Case Report Fellows may re-use this article for personal use and teaching without any further permission.

Become a Fellow of BMJ Case Reports today and you can:

- Submit as many cases as you like

- Enjoy fast sympathetic peer review and rapid publication of accepted articles

- Access all the published articles

- Re-use any of the published material for personal use and teaching without further permission

For information on Institutional Fellowships contact consortiasales@bmjgroup.com

Visit casereports.bmj.com for more articles like this and to become a Fellow 